www.jmscr.igmpublication.org

Impact Factor (SJIF): 6.379

Index Copernicus Value: 71.58

ISSN (e)-2347-176x ISSN (p) 2455-0450

crossref DOI: _https://dx.doi.org/10.18535/jmscr/v6i4.85

Journal Of Medical Science And Clinical Research

IGM Publication

An Official Publication of IGM Publication

\title{
Evaluation of the adverse drug reaction information for the multidrug resistant tuberculosis (MDR-TB) patients in a TB hospital in Mumbai
}

\section{(India)}

Authors

\section{Jaya Bajpai $^{1}$, Dr Rajendra Nanavare ${ }^{2}$, Dr Jagdish Keni ${ }^{3}$, Dr Deepa Arora ${ }^{4}$,} Dr Daksha Shah ${ }^{5}$, Dr Nilima A Kshirsagar ${ }^{6 *}$

${ }^{1}$ SRF under National Chair in Clinical Pharmacology ICMR New Delhi, Government of India, Office NIRRH, J.M Street, Parel, Mumbai, Maharashtra, India

${ }^{2}$ International Union against Tubercular and Lung Diseases, Mumbai, Maharashtra, India

3 Ex-Medical Supritendent, Group of Tuberculosis Hospital, Sewri, Mumbai - 400015, Maharashtra, India

${ }^{4}$ Vice President-Pharmacovigilance \& Global Head- Drug Safety \& Risk Management, LUPIN Limited,

Kalpataru Inspire, Santacruz (East), Mumbai - 400055, Maharashtra, India

${ }^{5}$ Deputy Executive Health Officer, Public Health Department, Municipal Corporation of Greater Mumbai

(MCGM), Mumbai - 400001, India

${ }^{6}$ National Chair in Clinical Pharmacology, ICMR, New Delhi, Government of India, Office NIRRH, J.M.

Street, Parel, Mumbai, Maharashtra, India

*Corresponding Author

Dr Nilima A Kshirsagar

National Chair in Clinical Pharmacology, ICMR, New Delhi, Government of India, Office NIRRH, J.M.

Street, Parel, Mumbai, Maharashtra, India

Email: kshirsagarna@yahoo.in

\begin{abstract}
Introduction: Second line drug treatment regimens for Drug Resistant Tuberculosis (DRTB) are lengthy and toxic, presenting a challenge to patient compliance. Information Education Communication (ICE) material usually lack information on Adverse Drug Reactions (ADRs) and prevention. To bridge this gap patient information sheet (PIS) on ADRs and preventability developed, has been field tested in this pilot study.

Methods: Prospective questionnaire based pilot study in DRTB patients in the TB hospital in Mumbai was conducted. Patients' response before and after reading the PIS, their knowledge about TB, ADR and preventability was evaluated.

Results: General knowledge about TB was good (>90\%) in the 62 patients (primary resistancel acquired resistance) who responded to the questionnaire before reading PIS. However their knowledge about ADR (50\%) and specific ADR (20\%) was low, which improved ADR (>90\%) and specific ADR (80\%) in the 23 patients who read the PIS and responded to questionnaire. PIS was found to be useful but lengthy.

Conclusion: Patients lack information on ADR and its prevention. PIS especially with pictorial presentation was good for communicating information, however needs to be shorter. Effect of PIS needs to be assessed on ADR incidence and compliance to treatment.

Keywords: Patient Information Sheet (PIS); Adverse Drug Reactions (ADRs); Tuberculosis; Central TB Division (CTD).
\end{abstract}




\section{Introduction}

Despite decades of research and availability of effective treatment regimens, tuberculosis (TB) is the ninth leading cause of death worldwide and the leading cause from a single infectious agent, ranking above HIV/AIDS ${ }^{1}$. About $3.3 \%$ of previously untreated and $20 \%$ of previously treated cases of TB had Multidrug-resistance TB $(\text { MDR-TB })^{2}$. MDR-TB, a disease caused by bacillus Mycobacterium tuberculosis strain resistant to at least rifampicin and isoniazid, is a globally growing threat that erodes the progress made in TB management ${ }^{3}$. The two reasons why multidrug resistance continues to emerge and spread are mismanagement of TB treatment and person-to-person transmission. (http://www.who.int/features/qa/79/en/)

Unlike the drug susceptible TB's six month course of first line drugs, the MDR-TB treatment with second-line drugs is costly, complicated and more importantly toxic. Most MDR-TB second line drugs treatment regimens last for more than 20 months, and present serious formidable challenge to ensure patient's adherence and cure rates in light of adverse drug reactions (ADRs) associated. Among several hurdles in a way to MDR-TB management, shortage of skilled health workers to manage the MDR-TB is also reported ${ }^{4}$. The utilization of second-line TB drugs for MDR-TB must include appropriate patient counselling, especially related to ADRs, for comprehensive long-term benefit in TB control ${ }^{5}$.

Adverse reactions to anti-TB drugs are related to various environmental and genetic factors. It is reported that the risk of ADRs is influenced with the patient's age ${ }^{6}$, malnutrition $^{7}$, alcoholism ${ }^{8}$, presence of pre-existing diseases or dysfunctions like impaired liver/kidney function, HIV coinfection $^{9,10}$ history of hepatitis ${ }^{11,12}$. The WHO treatment guidelines recommended regular monitoring and documentation to assess the response and to allow the identification and management of the ADRs. However, effective implementation of this is challenging in the resource poor settings like India.
One of the approaches to prevent and manage ADRs could be education and counselling of the patients at the time of their visit to the healthcare centre, through patient information sheet. A patient education program in a randomised control trial has shown increase in the adherence to the drug treatment for rheumatoid arthritis, persisting for 6 months ${ }^{13}$. Similarly, the patient information sheet for ADRs could also benefit in the prevention and management of ADRs related to anti-TB drugs. The current, revised National TB Control Program, India (RNTCP) sheets do not offer sufficient information regarding the ADRs to second line drugs. Hence the Indian Council of Medical Research (ICMR) along with Central TB Division (CTD) developed guidance and ready reckoner documents on ADR prevention and management for health workers, medical officers and TB specialists and patient information sheet (PIS) for preventing and managing side effects. This patient information sheet is available on the CTD website ${ }^{14}$. The purpose of the present study is to evaluate the PIS for its acceptability by the patient and its utility inpatient education, which will help in preventing the ADRs and improving compliance.

\section{Materials and Methods}

This was a prospective questionnaire based pilot study conducted at the Group of Tuberculosis hospital (GTB), Sewri, Mumbai during September to November 2016. GTB hospital is a specialized hospital for TB, run by Municipal Corporation of Greater Mumbai (MCGM) and is located in Mumbai, Maharashtra India. It has bed strength of 1200, out of which 1000 are reserved for drug sensitive patients and 200 for drug resistant patients.

Patient information sheet for ADR, prepared by ICMR, CTD and experts consists of general information, specific information of ADR occurrence and prevention. It is provided as a printed sheet with pictorial presentation of the ADRs. 
A partly open ended and partly closed ended structured questionnaire consisting of 10 questions was designed to assess the patient's knowledge regarding the basics of drug resistant tuberculosis (DR-TB), ADRs caused by anti- TB drugs and means to prevent the ADRs. As a pilot study sample size was decided to minimum 10 in primary and 10 in acquired resistance cases. As it was part of the RNTCP duty ethics committee, permission was not required. A total of $62 \mathrm{DR}-\mathrm{TB}$ patients were recruited from the out-patient department [OPD] randomly and were grouped as follows:

a. Primary resistance: Patient who have not received first line of treatment.

b. Acquired resistance: Patient who have acquired resistance to the first line treatment but not yet started the second line treatment.

The flow of patient in the OPD and the point of intervention are described in the Fig 1. Patients were interviewed while they were waiting for the group counselling i.e. when they have received some amount of information about the ADRs, while some of them were interviewed after they had received counselling i.e. group counselling/one to one counselling via social worker/doctor/nurse. Respondents were interviewed and their responses were recorded, they were then given the prepared PIS and the same set of questions for ADRs were repeated after they had read the PIS to assess if there was any improvement in their knowledge.PIS available in the Hindi and Marathi were provided in language of patients' choice.

\section{Questionnaire}

\section{Do you know that:}

1. You are suffering from TB?

2. TB is curable disease?

3. TB disease can be cured by medicines only?

4. Smoking and drinking should be avoided during TB medication?
5. TB medication has to be taken for at least 2 years, without interruption?

6. Any medication can have side effects?

7. TB medicines have side effects and can be prevented?

8. Any new symptoms/ adverse effects after consuming TB medicines are not necessarily due to TB medicines?

9. You might get following side effects* after consuming TB medicines?

*Vomiting, rashes, jaundice, joint pain, ringing ears, vision problem, anaemia, mood changes, flu like symptoms, any other (specify)

10. In case of any mentioned side effects or any new symptoms after consuming medicines, you should inform to doctor/healthcare provider and not discontinue treatment, one self?

Patients were asked about their general acceptability, (readability, clarity) and suggestions about the PIS. Illiterate patients were explained PIS with the help of pictorial presentation given in the PIS.

Demographic data such as age, gender, addiction, educational qualification, income were recorded from the respondents. The data so analysed is expressed in percentage.

\section{Results}

Sixty two patients participated in this survey study by giving verbal informed consent. Classification on the basis of characteristics is summarised in table 1 . Of 62 respondents, 34(54.8\%) were males and 28(45.16\%) were females. Mean body weight was $46.08 \pm 11 \mathrm{Kg}$ and the age ranged from 10 to 72 with the mean age of $30.7 \pm 15$ years.53(85.4\%) respondents were diagnosed as pulmonary, 8 $(12.9 \%)$ as extra pulmonary and 1 (1.6\%) diagnosed with pulmonary along with extra pulmonary. 28(45.16\%) were noted as primary resistance whereas $34(54.8 \%)$ were acquired resistance, $9.6 \%$ were illiterate.

\section{Pre Test knowledge about ADRs}

Response regarding knowledge about the general information of TB and ADRs associated with anti tubercular drugs is summarised in table 2. 
It was observed that the acquired resistance patients did not show any significant difference in knowledge regarding the basics of DR-TB, ADRs caused by anti- TB drugs and means to prevent the ADRs when compared to the responses of patients with primary drug resistant TB.

Of the 62 patients interviewed at the initiation of treatment only 33(53.2\%) respondents were aware that anti-TB drugs cause ADRs which can be prevented. 25(40.3\%) patients were of the opinion that the adverse reactions observed post anti-TB drug treatment were not caused by the anti-TB drugs. Only $18.2 \%$ and $23.2 \%$, of primary and acquired resistance patients respectively, were aware about the specific ADRs. Some of the ADRs reported by the patients included ringing in ears, vision problems and vomiting.
Post-test comparison of attitudes and knowledge of the respondents

Of the 62 respondents who participated in the pretest, only 33 respondents took the PIS, of whom only $23(37 \%)$ completed the post-test questionnaires (Table 3). Detailed response of the patients in individual categories post-test are summarised in Table 2.

Of the 23 respondents who completed the post-test questionnaires, in pre-test only 7 (20.5\%) were aware of the general information regarding antiTB drugs and 1 (44\%) was aware of the specific ADRs.

However these patients' knowledge improved after reading the PIS. It was seen that even those patients who presented with acquired resistance who had earlier already received anti-TB treatment were unaware of the ADRs and their knowledge improved after reading the PIS.

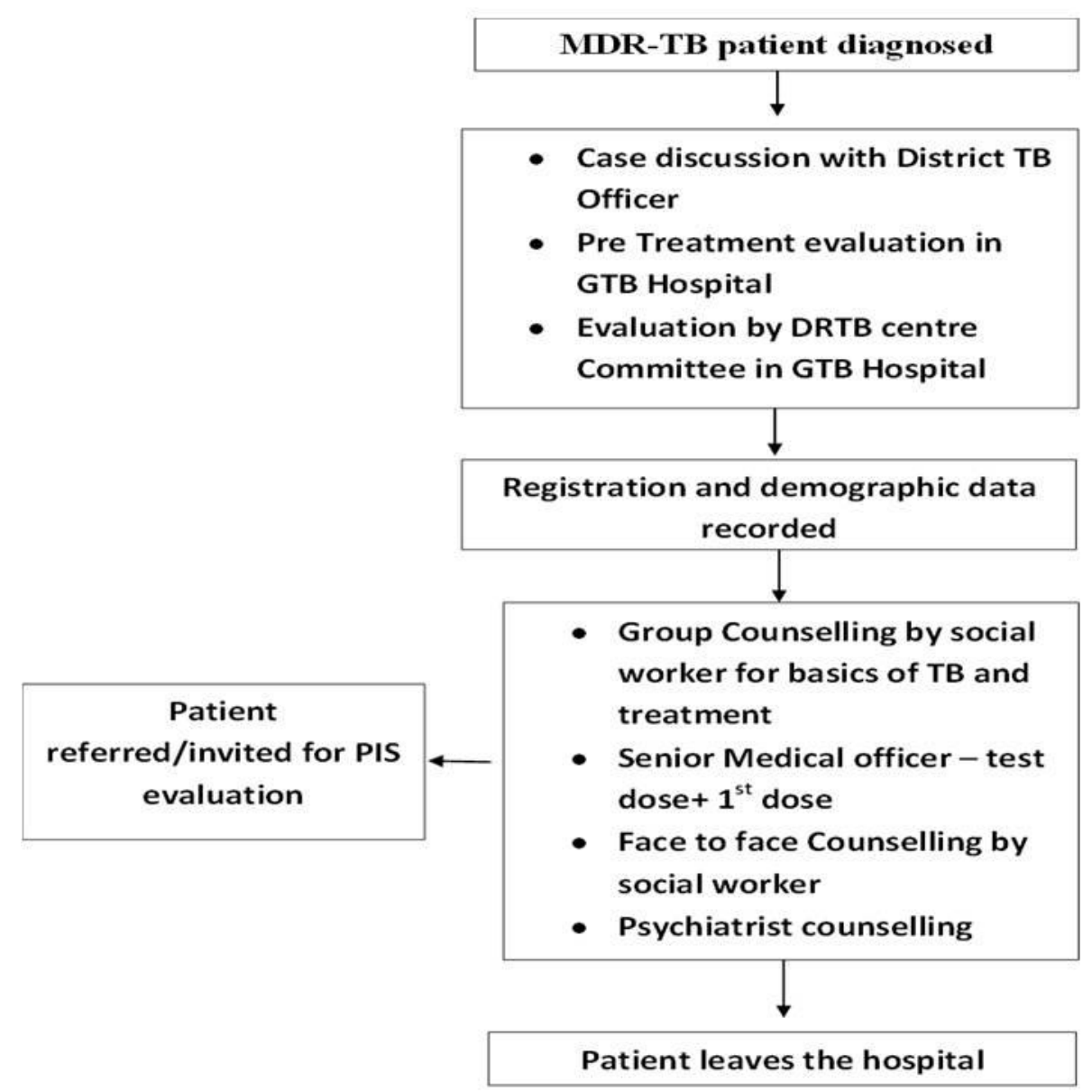

Fig 1 Patient Flow in OPD 
Table 1: Respondents Characteristic

\begin{tabular}{|l|c|}
\hline Characteristics & Patient candidate number (\%) \\
\hline Sex & $34(54.8)$ \\
Male & $28(45.2)$ \\
Female & \\
\hline Age(years) & $26(41.9)$ \\
Upto 25 & $36(58.1)$ \\
Above 25 & \\
Educational level & $6(9.6)$ \\
Illiterate & $16(25.8)$ \\
Primary & $26(41.9)$ \\
Secondary & $7(11.2)$ \\
Higher Secondary & $7(11.2)$ \\
Graduate & $24(38.7)$ \\
Employment status & $16(25.8)$ \\
Unemployed & $22(35.4)$ \\
Student & $\mathbf{9}(14.5)$ \\
Employed & $3(4.8)$ \\
Substance Abuse & $10(16.1)$ \\
Alcohol & \\
Smoking & $\mathbf{5 3}(\mathbf{8 5 . 4 )}$ \\
Tobacco & $\mathbf{8}(12.9)$ \\
Site of TB disease & $1(1.6)$ \\
Pulmonary & \\
Extra pulmonary & $28(45.2)$ \\
Pulmonary and Extra pulmonary & $34(54.8)$ \\
Classification by prior treatment history & \\
New Case (Primary resistance) & \\
Received first line drug (Acquired resistance) & \\
\hline
\end{tabular}

Table 2: Pre \& Post PIS patient response to questionnaire

\begin{tabular}{|c|c|c|c|c|c|}
\hline \multirow[t]{3}{*}{$\begin{array}{l}\text { Sr. } \\
\text { No. }\end{array}$} & \multirow{3}{*}{$\begin{array}{l}\text { Questions } \\
\text { Total subject }(n=62)\end{array}$} & \multicolumn{2}{|c|}{$\begin{array}{c}\text { Primary } \\
\text { Resistance }-\mathbf{n}(\%)\end{array}$} & \multicolumn{2}{|c|}{$\begin{array}{c}\text { Acquired } \\
\text { Resistance- n (\%) }\end{array}$} \\
\hline & & Pre PIS & Post PIS & Pre PIS & Post PIS \\
\hline & & $\mathrm{n}=28$ & $\mathrm{n}=11$ & $\mathrm{n}=34$ & $\mathrm{n}=12$ \\
\hline & & \multicolumn{4}{|c|}{ Subjects who replied affirmative } \\
\hline 1 & You are suffering from TB? & $27(96.4)$ & $11(100)$ & $34(100)$ & $12(100)$ \\
\hline 2 & Is TB curable? & $26(92.8)$ & $11(100)$ & $32(94.1)$ & $11(100)$ \\
\hline 3 & TB cured by medicines only? & $26(92.8)$ & $11(100)$ & $31(91.1)$ & $12(100)$ \\
\hline 4 & Smoking /alcohol should be avoided? & $26(92.8)$ & $11(100)$ & $27(79.4)$ & $12(100)$ \\
\hline 5 & $\begin{array}{l}\text { TB medicines to be taken continuously for } 2 \\
\text { years? }\end{array}$ & $24(85.7)$ & $11(100)$ & $32(94.1)$ & $12(100)$ \\
\hline 6 & Medicines have side effects? & $20(71.4)$ & $11(100)$ & $23(67.6)$ & $12(100)$ \\
\hline 7 & TB medicines have side effects? & $14(50)$ & $11(100)$ & $19(55.8)$ & $12(100)$ \\
\hline 8 & $\begin{array}{l}\text { All symptoms after treatment is started may } \\
\text { not be because of medicine? }\end{array}$ & $10(35.7)$ & $11(88.8)$ & $15(44.1)$ & $12(88.8)$ \\
\hline 9 & $\begin{array}{l}\text { ADRs Symptoms } \\
\text { Vomiting } \\
\text { Rashes } \\
\text { Jaundice } \\
\text { Joint pain } \\
\text { Ringing Ears } \\
\text { Vision Problem } \\
\text { Anaemia } \\
\text { Mood Changes } \\
\text { Flu like symptoms } \\
\text { Any other* }\end{array}$ & $\begin{array}{c}8(28.57) \\
7(25) \\
3(10.7) \\
7(25) \\
10(35.7) \\
9(32.1) \\
1(3.5) \\
3(10.7) \\
0(0) \\
3(10.7) \\
\end{array}$ & $\begin{array}{c}11(100) \\
10(90.9) \\
9(81.8) \\
11(100) \\
11(100) \\
10(90.9) \\
11(100) \\
8(72.7) \\
3(27.3) \\
7(70)\end{array}$ & $\begin{array}{c}13(38.2) \\
10(29.4 \%) \\
6(17.6 \%) \\
13(38.2 \%) \\
12(35.2 \%) \\
10(29.4 \%) \\
1(2.9 \%) \\
4(11.7 \%) \\
1(2.9 \%) \\
9(26.4 \%)\end{array}$ & $\begin{array}{c}12(90) \\
11(100) \\
12(91.6) \\
12(100) \\
10(100) \\
8(80) \\
3(25) \\
9(75) \\
5(41.6) \\
4(44.4)\end{array}$ \\
\hline & Total & $18.2 \%$ & $81.8 \%$ & $23.2 \%$ & $67.5 \%$ \\
\hline 10 & $\begin{array}{l}\text { Need to inform Doctor and not to stop } \\
\text { medication on our own? }\end{array}$ & $21(75)$ & & $25(73.5)$ & \\
\hline
\end{tabular}

*Any other: Numbness, Swelling, Dizziness, Low appetite, Nausea, Stomach ache, Kidney Problem 
Table 3 Participants information

\begin{tabular}{lccc}
\hline Patient Category & $\begin{array}{c}\text { Pre test } \\
\mathbf{n}(\boldsymbol{\%})\end{array}$ & $\begin{array}{c}\text { PIS taken by patient } \\
\mathbf{n}(\boldsymbol{\%})\end{array}$ & $\begin{array}{c}\text { Patient returned for Post } \\
\text { test } \mathbf{n}(\boldsymbol{\%})\end{array}$ \\
\hline Primary resistance & $28(45.2)$ & $16(25.8)$ & $11(17.7)$ \\
Acquired resistance & $34(54.8)$ & $16(25.8)$ & $12(19.3)$ \\
\hline Total & $\mathbf{6 2}(\mathbf{1 0 0})$ & $\mathbf{3 2}(\mathbf{5 1 . 6})$ & $\mathbf{2 3}(\mathbf{3 7})$ \\
\hline
\end{tabular}

\section{Discussion}

RNTCP India already has developed advertisements and pamphlets to inform general public about early diagnosis and complete treatment of TB with celebrities pronouncing "TB will lose, country will win" (TB Harega Desh Jeetega!) (https://www.tbcindia.gov.in/index1.php?lang=1\& level=3\&sublinkid=4667\&lid=3232). However information regarding ADRs is generally lacking. The PIS prepared by ICMR and CTD has tried to bridge this gap. In view of the paucity of manpower, printed PIS sheets were prepared for providing information to patient. The contents, presentation were reviewed and approved by ICMR, CTD and a committee of experts. This PIS has been field tested in present pilot study to assess if patients understood the information given in it.

This pilot study evaluated patient's knowledge about general information on TB specifically about ADR before and after reading PIS. Before PIS, most (>90\%) had general information about TB however fewer patients knew about avoiding smoking and alcohol (80-90\%) only half knew that TB drugs have side effects and 20\% knew about specific side effects.(there was no difference between those with primary and acquired resistance). This knowledge improved after reading PIS, with all patients knowing about ADR and $70-80 \%$ knowing specific ADRs. Patients commented that the PIS was too long though they said they could read it at home and it was a good idea. Half of the patients did not take the PIS or participate in the post PIS test probably because of the waiting and procedural long time required in the busy OPD.

Patients' general health beliefs are affected by their own experiences and fundamental understanding of health issues, often referred to as "health literacy". When health literacy rates are low, patients become more prone towards nonadherence with medical evaluations and treatment recommendations ${ }^{15}$.

Face-to-face discussions with patients and family members are vital towards patients achieving an adequate fundamental understanding of TB. Many factors contributing to persistent patient confusion include underlying health care anxiety; ethnic, cultural and language barriers; and information provided in an incomprehensive manner to patients with limited educational backgrounds.

Within busy hospital or outpatient clinic practices, health providers often will not have adequate time for more detailed discussions with their patients about TB. This particular problem is notably compounded among many TB clinics within lowand middle-income countries, where the incidence of TB is generally much higher compared to the U.S. The implementation of a low-cost educational strategy to improve the basic patient and family understanding of $\mathrm{TB}$ and the corresponding treatment plan would result in more effective and time-efficient management of TB patients.

Various strategies have been employed in an attempt to improve adherence to tuberculosis treatment. A Cochrane collaboration review assessed benefit of patient education and counselling for promoting adherence to treatment for tuberculosis in three randomized controlled trials involving 1437 patients with latent TB, Effects of different educational and counselling interventions, on proportion of patients who successfully completed treatment were evaluated. Counselling in Spain done by nurses via telephone improved it from $65 \%$ to $94 \%$, by nurses via home visits increased it to $95 \%$ and was better than physician counselling. In USA peer counselling for adolescent failed to show any benefit. In 
prisoners from USA, counselling improved it from $12 \%$ to $24 \%$. $^{16}$

In another recent review of publications on pharmacist delivered patient education on tuberculosis drug therapy, adherence was evaluated. Four articles with varying strength and weakness profile, one done in Turkey and three in USA showed overall improved medication adherence and treatment completion rates. ${ }^{17}$

However, considering the overall shortage of nurses and pharmacists in developing countries they can provide very limited time for counselling the patients and family. In a study evaluating effect of tuberculosis patients and family education through videography in 14 TB clinics in Elsalvador, patients' impression was evaluated ${ }^{18}$. They showed greater understanding of TB and improvement in compliance. Although there was a section in the video on common TB drug side effects and notifying the health providers if any adverse symptoms developed, this is not specifically evaluated. The study is based on subjective impressions. Patients' illiteracy is a problem. Video is a good method for communication to such patients. However it has limitations due to non-availability of video player in patients home.

Printed pamphlet can be read by patients and relatives in their homes at their own convenience. In our study we found $9 \%$ of our patients were illiterate, pictorial representations was useful for such patients. Patients appreciated the pictorial presentation however found the PIS to be too lengthy.

Aim of our pilot study was to evaluate acceptability of PIS by patient and if they understood the content. The weakness of our study is that patient's knowledge was tested and not actual compliance. It was tested immediately after reading PIS hence effect on retention of knowledge was not checked. The study brings out the need of pilot field testing before making PIS widely available. Based on the results of this pilot study results, the PIS will be suitably shortened. The study shows that while general media propaganda about TB has had effect so that patients do have general information about TB, most lack information about $\mathrm{ADR}$ and how to prevent them.

In the current on-going conditional access program for bedaquiline, ADRs have been noted which can be prevented by providing information to patients and relatives (eg. about managing diarrhoea and vomiting and using ORS).ADR monitoring management, prevention and reporting in public health programs is becoming important as drugs which are active against drug resistant microbes but have greater side effects are being used. Empowering patients with knowledge would help prevent ADRs and improve acceptance.

\section{Conclusion}

Most TB patients have good general information about TB; however their knowledge about ADRs and preventability of ADR is low. This affects compliance and results in poor outcome. Patient information sheet vetted by ICMR, CTD and experts, with general information about $\mathrm{TB}$ and specific information on ADR and prevention was field tested in the pilot study in patients with DR TB. Patients' knowledge about ADR which was low before PIS improved after reading PIS. PIS was appreciated, but was found to be rather lengthy by patients. With shortage of trained man power, providing PIS would be useful way of communication. Further work on improving the presentation and testing benefit of PIS on compliance will be done in future.

\section{Acknowledgements}

We are grateful to all contributors and experts from ICMR, CTD and Lupin Limited for the development of PIS and Group of Tuberculosis hospital (GTB), Sewri, Mumbaifor the conduct of study. Help by Dr. Sagar Bacchav in preparing this manuscript is gratefully acknowledged.

\section{References}

1. World Health Organisation. Global TB report 2017. WHO/HTM/TB/2017.23 
2. World Health Organisation. Global TB report 2015. WHO/HTM/TB/2015.22

3. Sharma SK, Mohan A. Multidrug-resistant tuberculosis (Review article). Indian Journal of Medical Research 2004: 120:354-376.

4. Towards universal access to diagnosis and treatment of multidrug-resistant and extensively drug-resistant tuberculosis by 2015. WHO PROGRESS REPORT 2011. WHO/HTM/TB/2011.3

5. Dye C, Williams BG, Espinal MA, Raviglione MC. Erasing the world's slow stain: strategies to beat multidrug-resistant tuberculosis. Science 2002: 295:2042-2046. doi:10.1126/science.1063814

6. Kaplowitz N. Causality assessment versus guilt- by- association in drug hepatotoxicity. Hepatology 2001:33:308310.doi:10.1053/jhep.2001.21083

7. Fernandez-Villar A, Sopena B, FernandezVillar J, Vazquez-Gallardo R, Ulloa F, Leiro V, Mosteiro M, Pineiro L. The influence of risk factors on the severity of antituberculosis drug-induced hepatotoxicity. The International Journal of Tuberculosis and Lung Disease 2004: 8:1499-1505.

8. Pande J N, Singh S P, Khilnani G C, Khilnani S, Tandon R K. Risk factors for hepatotoxicity from antituberculosis drugs: a case-control study. Thorax 1996: 51: 132136.

9. Yee D, Valiquette C, Pelletier $\mathrm{M}$, et al. Incidence of serious side effects from firstline antituberculosis drugs among patients treated for active tuberculosis. American Journal of Respiratory and Critical Care Medicine 2003: 167: 1472-1477. doi: 10.1164/rccm.200206-626OC

10. Ungo J, Jones D, Ashkin D, et al. A. Antituberculosis drug induced hepatotoxicity. The role of hepatitis $\mathrm{C}$ virus and the human immunodeficiency virus. American Journal of Respiratory and Critical Care Medicine 1998: 157: 1871-1876.
11. Schaberg T, Rebhan K, Lode H. Risk factors for side-effects of isoniazid, rifampin and pyrazinamide in patients hospitalized for pulmonary tuberculosis. European Respiratory Journal 1996: 9:2026-2030.

12. Teleman M, Chee CB, Earnest A, Wang Y. Hepatotoxicity of tuberculosis chemotherapy under general programme conditions in Singapore. The International Journal of Tuberculosis and Lung Disease 2002: 6:699-705.

13. Hill J, Bird H, Johnson S. Effect of patient education on adherence to drug treatment for rheumatoid arthritis: a randomised controlled trial. Annals of the rheumatic diseases 2001:60:869-875.

14. ICMR and central TB division India :Prevention and Management of Adverse Reactions associated with Antitubercular Drugs .Patient Guide, 2016, https://tbcindia.gov.in.

15. Martin LR, Williams SL, Haskard KB, DiMatteo MR. The challenge of patient adherence. Therapeutics and clinical risk management 2005:1:189-199

16. M'Imunya JM, Kredo T, Volmink J. Patient education and counselling for promoting adherence to treatment for tuberculosis (Review article). The Cochrane Library. 2012 .doi: 10.1002/14651858.CD006591.

17. Schmitz DM, Fleissner D, Tran A. Impact of Pharmacist-Delivered Patient Education on Tuberculosis Drug Therapy Adherence. ADVANCES in pharmacy 2017:1.

18. Wilson JW, Ramos JG, Castillo F, Castellanos EF, Escalante P. Tuberculosis patient and family education through videography in El Salvador. Journal of Clinical Tuberculosis and Other Mycobacterial Diseases 2016:4:14-20. doi.org/10.1016/j.jctube.2016.05.001 